\title{
Socioeconomic and race/ethnic differences in daily salivary cortisol profiles: The Multi-Ethnic Study of Atherosclerosis
}

\author{
Anjum Hajat ${ }^{a, *}$, Ana Diez-Roux ${ }^{a}$, Tracy G. Franklin ${ }^{a}$, Teresa Seeman ${ }^{b}$, \\ Sandi Shrager ${ }^{c}$, Nalini Ranjit ${ }^{d}$, Cecilia Castro ${ }^{e}$, Karol Watson ${ }^{f}$, \\ Brisa Sanchez ${ }^{\mathrm{g}}$, Clemens Kirschbaum ${ }^{\mathrm{h}}$
}

\begin{abstract}
a University of Michigan, School of Public Health, Department of Epidemiology, 109 Observatory, 3rd Floor Tower, Ann Arbor, Ml 48109-2029, United States

${ }^{\mathrm{b}}$ David Geffen School of Medicine at UCLA, Department of Medicine, Division of Geriatrics, 10945 Le Conte Avenue, Los Angeles, CA 90095, United States

' University of Washington, Department of Biostatistics, Collaborative Health Studies Coordinating Center, 6200 NE 74th Street, Seattle, WA 98115, United States

${ }^{\mathrm{d}}$ University of Texas Health Sciences Center, School of Public Health, 1200 Herman Pressler Drive, Houston, TX 77030, United States

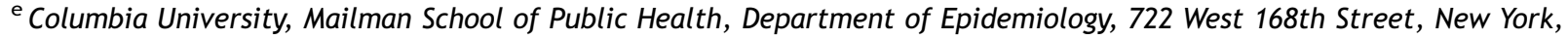
NY 10032, United States

${ }^{f}$ David Geffen School of Medicine at UCLA, Department of Medicine, Division of Cardiology, 200 ucla Medical Plaza, Los Angeles, CA 90095-1679, United States

${ }^{\mathrm{g}}$ University of Michigan, School of Public Health, Department of Biostatistics, 1420 Washington Heights, Ann Arbor, Ml 48109-2029, United States

${ }^{\mathrm{h}}$ Technische Universität Dresden, Department of Psychology, 01062 Dresden, Germany
\end{abstract}

Received 27 July 2009; received in revised form 19 October 2009; accepted 14 December 2009

\section{KEYWORDS}

Salivary cortisol;

Cortisol diurnal pattern;

Race/ethnicity;

Socioeconomic status;

Cortisol awakening

response;

Stress

\begin{abstract}
Summary It has often been hypothesized that stress and its biological consequences mediate the relationship between low socioeconomic status (SES) or minority status and poor cardiovascular disease outcomes. The objective of this study was to determine if daily cortisol patterns, a biomarker of the stress response, differ by race/ethnicity and socioeconomic status. Data were collected from 935 Black, White and Hispanic adults age 48-90 years old. Salivary cortisol samples were collected six times per day over 3 days: at awakening, 30 min later, at $1000 \mathrm{~h}$, noon, $1800 \mathrm{~h}$ and at bedtime. Blacks and Hispanics had lower levels of wake-up cortisol and less steep early declines, while Blacks had flatter and Hispanics steeper late day declines relative to Whites. Similarly the low socioeconomic status group also had lower levels of wake-up cortisol and less
\end{abstract}

\footnotetext{
* Corresponding author at: University of Michigan, School of Public Health, Department of Epidemiology, Center for Social Epidemiology and Population Health, 109 Observatory Street, 3rd Floor Tower, Room 3620w1, Ann Arbor, Ml 48109-2029, United States. Tel.: +1 734 615 9228; fax: +1 7347635706

E-mail address: ahajat@umich.edu (A. Hajat).
} 
steep decline during the early part of the day. These patterns remained after adjustment for health behaviors and psychosocial factors. This study finds an association between salivary cortisol and race/ethnicity and SES in a multi-ethnic study population. Further work is needed to determine the health consequences of these differences.

(C) 2009 Elsevier Ltd. All rights reserved.

\section{Introduction}

It has often been hypothesized that stress and its biological consequences are one potential mechanism by which low socioeconomic status (SES) or minority status result in poor cardiovascular disease outcomes (Brunner, 1997; Baum et al., 1999; Steptoe and Marmot, 2002). Minorities and the poor are hypothesized to feel a greater degree of chronic stress resulting from both an increased exposure to stressful events and fewer social and material resources with which to combat the effects of chronic stress (Adler et al., 1994; Baum et al., 1999; Pearlin et al., 2005). These stressors have biological consequences, such as alterations in the levels of stress hormones, resulting from activation of the hypothalamic-pituitary-adrenal (HPA) axis and sympathetic nervous system (Cohen et al., 1995). Although evidence is still sparse, cortisol, one of the key hormones released in response to stressors, has been linked to a number of cardiovascular risk factors. For example, increases in cortisol have been linked to CVD risk factors such as central adiposity (Bjorntorp, 1997; Epel et al., 2000), hypertension (Rosmond and Bjorntorp, 2000; Hammer and Stewart, 2006) and inflammation (Petrovsky et al., 1998; Miller et al., 2002), as well as early indicators of atherosclerosis such as increased intima media thickness (Eller et al., 2001) and coronary calcification (Matthews et al., 2006).

Cortisol levels rise sharply during the first $30-45 \mathrm{~min}$ immediately after awakening, known as the cortisol awakening response (CAR), and then decline gradually over the day (with some oscillations around meal time) reaching their lowest daily level late in the evening. It is still uncertain which specific features of the daily cortisol profile may be most relevant to health outcomes; however, several features have been examined in relation to SES and race/ethnicity. Features of the daily cortisol curve examined in the literature include wake-up levels (Steptoe et al., 2003; Kunz-Ebrecht et al., 2004; Ranjit et al., 2005a; Wright and Steptoe, 2005; Cohen et al., 2006a,b; Eller et al., 2006) the CAR (Steptoe et al., 2003, 2005; Bennett et al., 2004; Kunz-Ebrecht et al., 2004; Wright and Steptoe, 2005; Cohen et al., 2006b; Eller et al., 2006; Garcia et al., 2008) and the diurnal cortisol slope (Ockenfels et al., 1995; Steptoe et al., 2005; Cohen et al., 2006a,b; DeSantis et al., 2007).

Although there is some evidence of differences in daily cortisol profiles by race/ethnicity or SES, results have not always been consistent. For example, some studies found no association between SES and cortisol levels at wake-up (KunzEbrecht et al., 2004; Ranjit et al., 2005a; Wright and Steptoe, 2005; Cohen et al., 2006a,b; Eller et al., 2006), while others found higher wake-up cortisol levels among higher SES groups (Brandtstädter et al., 1991; Steptoe et al., 2003; Bennett et al., 2004). The picture for CAR is even less consistent: some studies find no association (Steptoe et al., 2003, 2005; Cohen et al., 2006b; Eller et al., 2006; Garcia et al., 2008), others find a steeper CAR among high SES groups (Bennett et al., 2004; Ranjit et al., 2005a) and still others a flatter CAR among high SES groups (Kunz-Ebrecht et al., 2004; Steptoe et al., 2005; Wright and Steptoe, 2005). As for the diurnal slope, a few studies found no association between cortisol and SES (Steptoe et al., 2005; Cohen et al., 2006a). Others found flatter slopes for low SES groups (Cohen et al., 2006b) and minorities (DeSantis et al., 2007), while one study found the unemployed had steeper slopes compared to the employed (Ockenfels et al., 1995). Establishing whether daily cortisol profiles are patterned by SES and race/ethnicity would provide support for the hypothesis that stress may mediate disparities in cardiovascular disease (and perhaps other outcomes). In addition, identifying the specific features of the daily cortisol curve that are most affected by SES and race/ethnicity could also provide clues regarding the features of the curve (and the biological mechanisms) most relevant to understanding how chronic stress affects health.

Using data from a large and diverse population-based sample with multiple timed measures of cortisol over 3 days, we examined the SES and race/ethnic patterning of various features of the daily cortisol profile. Although several studies have documented the effect of SES and race/ethnicity on diurnal cortisol pattern, the current study addresses important limitations of prior studies including small sample sizes, around 250 or less (Ockenfels et al., 1995; Decker, 2000; Steptoe et al., 2003, 2005; Bennett et al., 2004; KunzEbrecht et al., 2004; Ranjit et al., 2005a; Wright and Steptoe, 2005; Cohen et al., 2006a; Eller et al., 2006; DeSantis et al., 2007; Garcia et al., 2008), selected populations and convenience sampling (e.g. only young or old adults, only women) (Ockenfels et al., 1995; Bennett et al., 2004; Ranjit et al., 2005a; Wright and Steptoe, 2005; Cohen et al., 2006a; Eller et al., 2006; DeSantis et al., 2007; Garcia et al., 2008), and limited numbers of cortisol measures and days of assessment per subject (Brandtstädter et al., 1991; Decker, 2000; Bennett et al., 2004; Cohen et al., 2006a,b; Li et al., 2007).

\section{Methods}

The Multi-Ethnic Study of Atherosclerosis (MESA) is a longitudinal study, funded by the National Heart Lung and Blood Institute designed to investigate risk factors for subclinical cardiovascular diseases and its progression to clinical disease. At baseline MESA included 6814 men and women aged 44-84 years without clinical cardiovascular disease recruited from six sites. At each site a probability sample of participants was selected through a variety of population-based approaches, including lists of area residents, area residents enrolled in a union health plan, random digit dialing and lists from the Centers for Medicare and Medicaid Services for participants 65 or older (Bild et al., 2002).

An ancillary study to MESA, the MESA Stress study collected detailed measures of stress hormones, including sali- 
vary cortisol measures, on a subsample of 1002 participants enrolled at the New York and Los Angeles MESA sites. All procedures were carried out with the adequate understanding and written consent of the subjects. These data were collected in conjunction with the third and fourth follow-up exams of the full MESA cohort between 2004 and 2006. Participants were enrolled in the order in which they attended the follow-up exam. Enrollment continued until approximately 500 participants were enrolled at each site. This procedure resulted in an approximately random sample of white, black and Hispanic participants from each site. Compared to other eligible participants at the two sites, the MESA Stress study was similar to the parent study, with a few exceptions. There were fewer persons in the $75-84$ years age range $(12.1 \%$ compared to $18.2 \%$ in the overall MESA study), slightly more men (47.6\% compared to $44.7 \%)$ and more participants with some college education $(29.7 \%$ compared to $23.9 \%$ ).

Each MESA Stress participant was instructed to collect six saliva samples per day over 3 weekdays, resulting in a maximum of 18 samples per person. The first sample was to be taken immediately after waking (and before getting out of bed), the second sample 30 min later, the third sample at around $1000 \mathrm{~h}$, the fourth sample at around $1200 \mathrm{~h}$ (or before lunch if lunch occurred before noon), the fifth sample at around $1800 \mathrm{~h}$ (or before dinner if dinner occurred before 6 $\mathrm{pm})$, and the sixth sample right before bed. Detailed instructions and training in sample collection were provided to participants by trained staff.

Saliva samples were collected using Salivette collection tubes and stored at $-20{ }^{\circ} \mathrm{C}$ until analysis. Before biochemical analysis, samples were thawed and centrifuged at $3000 \mathrm{rpm}$ for $3 \mathrm{~min}$ to obtain clear saliva with low viscosity. Salivary cortisol levels were determined employing a commercially available chemi-luminescence assay (CLIA) with high sensitivity of $0 / 16 \mathrm{ng} / \mathrm{mL}$ (IBL-Hamburg; Germany). Intra- and inter-assay coefficients of variation were below eight percent. Cortisol was measured in nmol per liter.

Participants recorded the collection time of salivary samples on special cards; in addition a container with a time tracking device (known as track-caps) automatically registered the time at which cotton swabs were extracted to collect each sample. Participants were told of this time tracking device. Prior work has shown that the use of this device increases compliance with the requested timing of samples (Kudielka et al., 2003). At the end of each day participants completed a short daily questionnaire including their wake-up time on that day and whether they had been able to collect the first sample immediately after wake-up.

We examined education, income and wealth as SES variables. Education was defined as the participant's highest level of education and was categorized as less than or equal to high school, some college or greater than or equal to bachelor's degree. The wealth measure was derived based on ownership of the following assets: owning one or more car, owning a home or paying mortgage on a home, owning land or owning an investment (such as stocks, bonds, mutual funds, retirement investments). A 5-point wealth index was created, where 1 point was given for ownership of the above mentioned assets. Families who owned all of these assets received a score of four and those who owned none received a score of zero. Total annual family income was obtained through questionnaire, in 13 categories ranging from less than $\$ 5000$ to greater than $\$ 100,000$. In order to adjust family income for the number of people living in the household, a family income of less than $\$ 5000$ was assigned a family income of $\$ 2500$ and greater than $\$ 100,000$ was assigned an income of $\$ 112,500$. For all other income categories the midpoint of the category was used. Family income was then divided by 10,000 and categorized into quintiles (zero being the poorest and four the richest). An income-wealth index was created by summing the five category per capita income variable and the 5-point wealth index, yielding an incomewealth index with a total of 9 points ranging from zero to eight. Those with an annual per capita family income in the lowest quintile and no assets received a score of zero and those with income in the highest quintile and all four assets received a score of eight. This scored variable was specified as continuous in regression models. Income and wealth data collected at exam three were used in this analysis, but any missing data were imputed from previous waves. Race/ethnicity was reported by participants in response to questions modeled on the year 2000 Census and was categorized into white, black, and Hispanic.

Previous research has found age and gender to be associated with cortisol levels (Clow et al., 2004; Ranjit et al., 2005b; Cohen et al., 2006a; Hansen et al., 2008). Hence continuous age and gender were adjusted for in all models. Other behavioral factors such as smoking, exercise and body mass index have also been shown to be associated with cortisol levels (Clow et al., 2004; Ranjit et al., 2005b; Cohen et al. , 2006a; Hansen et al. , 2008). In our data, all behavioral variables were also associated with both race and incomewealth. Since these behavioral variables could be confounders and/or mediators of stress effects on cortisol, we reported estimates before and after adjustment for these covariates. Smoking was categorized into current, past, or never. Body mass index (BMI) was calculated as weight in kilograms divided by height in meters squared and was modeled as standard categories: normal, overweight (BMI between 25 and 29.9) and obese (BMI > 30). Physical activity questions were adapted from the Cross-Cultural Activity Participation Study (Irwin et al., 2000). Higher scores of intentional exercise, measured in metabolic equivalent (MET)-minutes/week, indicated higher levels of moderate and vigorous activities. Intentional exercise was categorized into approximate quartiles, where the first quartile was composed of all those who reported no exercise, about $25 \%$ of the study population.

Several psychosocial factors were also explored as potential confounders or mediators, namely hostility, depression, emotional support and chronic burden. Much previous research has linked cortisol to these factors (Pope and Smith, 1991; Yehuda et al., 1996; Pruessner et al., 2003; Cohen et al., 2006b; Sjogren et al., 2006; Ranjit et al., 2009) and our data also supported their association with SES. Cynical hostility was derived from an 8-item subscale of the full CookMedley Hostility Scale and is a key component of hostility (Barefoot et al., 1989) that has been linked to salivary cortisol in earlier studies (Pope and Smith, 1991; Ranjit et al., 2009). Depression was measured by summing the 20-item Center for Epidemiologic Studies Depression scale (Radloff, 1977). Emotional social support was derived by summing a 6-item scale and chronic burden was derived from 
Table 1 Selected characteristics of cortisol data collection by demographic characteristics for MESA Stress Study participants.

\begin{tabular}{|c|c|c|c|c|c|c|c|c|}
\hline & $\begin{array}{l}\text { Percent } \\
\text { distribution } \\
\text { of participants }\end{array}$ & $\begin{array}{l}\text { Percent of } \\
\text { participants } \\
\text { with five or } \\
\text { more samples } \\
\text { on all days }{ }^{\text {a }}\end{array}$ & $\begin{array}{l}\text { Percent of } \\
\text { samples with } \\
\text { reported times } \\
\text { within } 15 \text { min of } \\
\text { track-caps times }^{\text {b }}\end{array}$ & $\begin{array}{l}\text { Percent of } \\
\text { days for which } \\
\text { first sample was } \\
\text { taken within } \\
5 \text { min of wake-up }\end{array}$ & $\begin{array}{l}\text { First sample } \\
\text { time (median) }\end{array}$ & $\begin{array}{l}\text { Last } \\
\text { sample } \\
\text { time } \\
\text { (median) }\end{array}$ & $\begin{array}{l}\text { Difference } \\
\text { between first } \\
\text { and second } \\
\text { sample time } \\
\text { (median) }\end{array}$ & $\begin{array}{l}\text { Cortisol area } \\
\text { under the } \\
\text { curve }^{\text {d }} \\
\text { (median) }\end{array}$ \\
\hline All subjects $(n=935)$ & $100.0 \%$ & $85.2 \%$ & $86.0 \%$ & $78.2 \%$ & $6: 42$ & $22: 26$ & $0: 34$ & 6270 \\
\hline \multicolumn{9}{|l|}{ Site } \\
\hline New York & $51.9 \%$ & $86.0 \%$ & $86.6 \%$ & $77.7 \%$ & $6: 49$ & $22: 46$ & $0: 34$ & 6403 \\
\hline Los Angeles & $48.1 \%$ & $84.4 \%$ & $85.1 \%$ & $78.7 \%$ & $6: 36$ & 22:07 & $0: 35$ & 6112 \\
\hline$p$-Value $e^{e}$ & & 0.5085 & 0.0084 & 0.5146 & 0.0683 & 0.0313 & 0.5319 & 0.4893 \\
\hline \multicolumn{9}{|l|}{ Age } \\
\hline $48-54$ & $17.0 \%$ & $86.8 \%$ & $87.1 \%$ & $88.4 \%$ & $6: 33$ & $22: 45$ & $0: 33$ & 5562 \\
\hline $55-64$ & $31.1 \%$ & $85.2 \%$ & $86.9 \%$ & $77.6 \%$ & $6: 32$ & $22: 24$ & $0: 34$ & 6122 \\
\hline $65-74$ & $33.1 \%$ & $86.7 \%$ & $86.0 \%$ & $76.6 \%$ & $6: 47$ & $22: 25$ & $0: 36$ & 6380 \\
\hline $75-89$ & $18.8 \%$ & $81.3 \%$ & $82.9 \%$ & $72.8 \%$ & $6: 53$ & $22: 23$ & $0: 35$ & 6924 \\
\hline$p$-Value $e^{\mathrm{e}}$ & & 0.2638 & $<0.0001$ & $<0.0001$ & 0.0051 & 0.1615 & 0.3855 & 0.0003 \\
\hline \multicolumn{9}{|l|}{ Sex } \\
\hline Female & $51.6 \%$ & $84.2 \%$ & $86.1 \%$ & $79.2 \%$ & $6: 40$ & $22: 25$ & $0: 35$ & 5859 \\
\hline Male & $48.5 \%$ & $86.3 \%$ & $85.7 \%$ & $77.2 \%$ & $6: 45$ & $22: 29$ & $0: 34$ & 6689 \\
\hline$p$-Value & & 0.3699 & 0.5702 & 0.2027 & 0.9091 & 0.0750 & 0.0595 & 0.1030 \\
\hline \multicolumn{9}{|l|}{ Race } \\
\hline White & $19.6 \%$ & $85.3 \%$ & $89.1 \%$ & $86.2 \%$ & $6: 45$ & $22: 44$ & $0: 33$ & 7048 \\
\hline Black & $27.6 \%$ & $84.9 \%$ & $85.2 \%$ & $73.4 \%$ & $6: 58$ & $22: 51$ & $0: 35$ & 6300 \\
\hline Hispanic & $52.8 \%$ & $85.4 \%$ & $85.1 \%$ & $77.7 \%$ & $6: 32$ & $22: 10$ & $0: 35$ & 5935 \\
\hline$p$-Value $e^{e}$ & & 0.9804 & $<0.0001$ & $<0.0001$ & 0.6883 & 0.1798 & 0.1514 & 0.0017 \\
\hline \multicolumn{9}{|c|}{ Total gross family income } \\
\hline$<\$ 25,000$ & $39.5 \%$ & $83.0 \%$ & $82.8 \%$ & $73.4 \%$ & $6: 45$ & $22: 05$ & $0: 37$ & 6152 \\
\hline$\$ 25-49,999$ & $32.6 \%$ & $88.9 \%$ & $87.6 \%$ & $80.2 \%$ & $6: 39$ & $22: 37$ & $0: 34$ & 6208 \\
\hline$\geqq \$ 50,000$ & $27.9 \%$ & $85.0 \%$ & $88.5 \%$ & $83.1 \%$ & $6: 42$ & $22: 44$ & $0: 33$ & 6543 \\
\hline$p$-Value $e^{e}$ & & 0.3694 & $<0.0001$ & $<0.0001$ & 0.1008 & 0.0035 & 0.5271 & 0.8716 \\
\hline \multicolumn{9}{|l|}{ Wealth } \\
\hline 0 assets & $18.2 \%$ & $82.9 \%$ & $83.9 \%$ & $75.3 \%$ & $6: 48$ & $22: 13$ & $0: 37$ & 6167 \\
\hline 1 assets & $25.2 \%$ & $85.2 \%$ & $83.0 \%$ & $78.6 \%$ & $6: 42$ & $22: 32$ & $0: 34$ & 6157 \\
\hline 2 assets & $24.2 \%$ & $86.3 \%$ & $86.5 \%$ & $79.3 \%$ & $6: 38$ & $22: 21$ & $0: 34$ & 6219 \\
\hline 3 assets & $20.2 \%$ & $86.8 \%$ & $89.7 \%$ & $79.5 \%$ & $6: 42$ & $22: 26$ & $0: 34$ & 6292 \\
\hline 4 assets & $12.2 \%$ & $84.2 \%$ & $87.3 \%$ & $77.4 \%$ & $6: 41$ & $22: 35$ & $0: 34$ & 6696 \\
\hline$p$-Value $e^{\mathrm{e}}$ & & 0.5391 & $<0.0001$ & 0.3203 & 0.0846 & 0.3911 & 0.6958 & 0.6506 \\
\hline \multicolumn{9}{|l|}{ Income-wealth index } \\
\hline $0-1$ points & $19.6 \%$ & $84.2 \%$ & $81.4 \%$ & $75.2 \%$ & $6: 42$ & $22: 13$ & $0: 39$ & 5923 \\
\hline $2-3$ points & $28.9 \%$ & $84.0 \%$ & $83.9 \%$ & $75.8 \%$ & $6: 47$ & $22: 07$ & $0: 35$ & 6105 \\
\hline
\end{tabular}




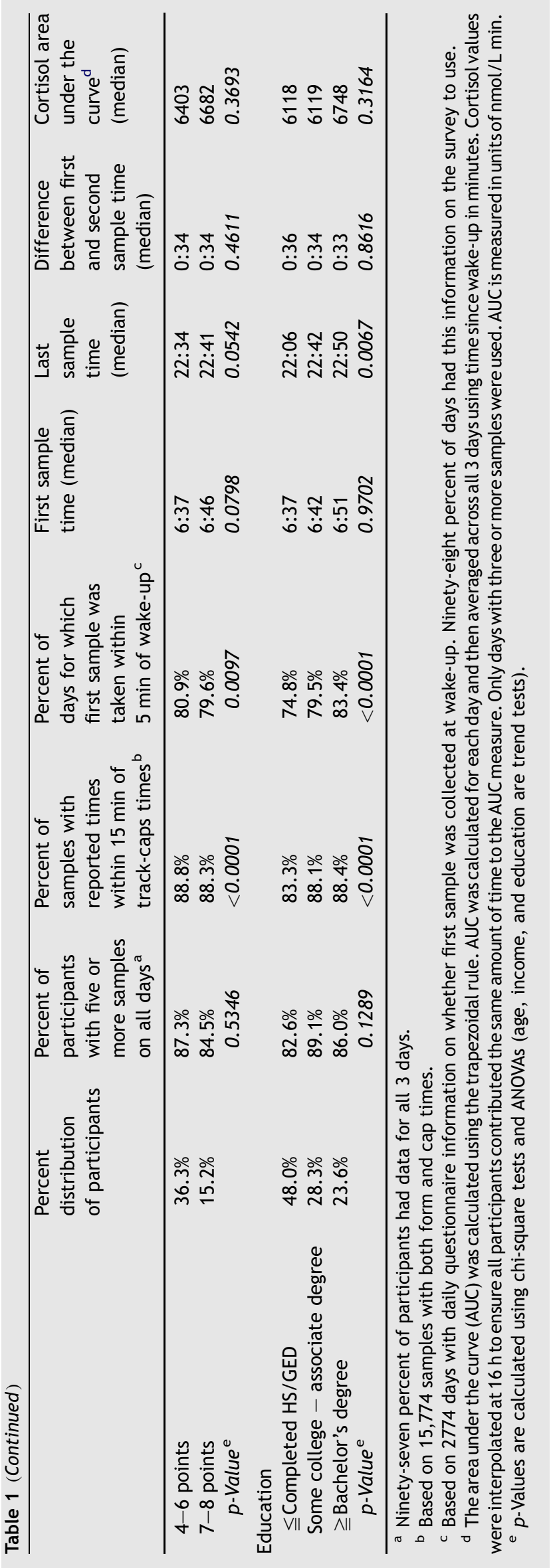

a 5-item scale regarding difficulties in five separate domains of life (Bromberger and Matthews, 1996). All four variables were specified as continuous.

We first examined selected characteristics of sample collection and cortisol levels by site, age, sex, race/ethnicity and SES indicators. Due to its skewed distribution cortisol was log transformed for analysis. Up to 18 measures collected over the 3 days were included for each person. Exploratory data analyses including locally estimated scatter plot smoothing (LOESS) curves were used to examine the shape of the cortisol profile over the course of the day for the full sample and stratified by age, gender, race/ethnicity and SES. LOESS models are a nonparametric regression method which fit models to localized subsets of data. This allows greater flexibility because no assumptions about the global form of the regression surface are needed (Cleveland et al., 1988; Devlin and Cleveland, 1988).

Based on these descriptive analyses and the shape of the LOESS plots, and in order to capture the non-linearity of cortisol over the day, knots were selected to describe a piecewise linear regression. Two fixed knots, at 30 min after wake-up and 120 min after wake-up, were used to model cortisol levels. Inclusion of the second knot (120 min) substantially improved the fit of the model, especially for the early part of the day. Results were robust to alternate specifications of the second knot.

In regression analyses, within-person correlations and person-to-person variation in slopes were accounted for by using mixed models and allowing random components for the person specific intercept and person specific slopes. The between day variability in our data was small (and the addition of a random component for day resulted in nonconvergent models), thus we did not model day as a random effect. Instead day level variability was addressed through the use of the day variable as a fixed effect and through the use of robust standard errors. The inclusion of random components for all three slopes led to convergence problems so only the first and third slopes were modeled as random. Results were invariant regardless of which of the two slopes were modeled as random. An unstructured covariance matrix was used to obtain robust standard errors. Models also controlled for day (first, second or third day of data collection) and wake-up time. Main effects of covariates as well as their interactions with different pieces of the daily slope were included to estimate adjusted associations of SES and race/ ethnicity with the shape of the cortisol profile. Since all cortisol values were log transformed, exponentiated coefficients from the models were interpreted as percent differences.

In addition to modeling log cortisol values over time, we estimated an area under the curve (AUC) measure for each day where a participant collected at least three cortisol samples. AUC is a summary measure that represents the total amount of cortisol measured over the course of the day and was calculated using the trapezoidal rule; where the area under the curve was divided into several trapezoids, and a total AUC was obtained as the sum of the areas of these individual trapezoids (Yeh and Kwan, 1978). Time, on the $x$ axis, was measured in minutes since wake-up. AUC was calculated for the period between wake-up and $16 \mathrm{~h}$ after wake-up to ensure that each participant contributed the same number of waking hours to the measure. Cortisol values 
for $16 \mathrm{~h}$ were linearly interpolated based on adjacent values. Because it is a summary measure, cortisol values were not log transformed when calculating the AUC, which is in units of $\mathrm{nmol} / \mathrm{L}$ min. Mixed models with random intercepts (to account for within-person correlations in the three daily measures) were used to model AUC as a function of SES and race/ethnicity adjusted for covariates.

All times used in analyses were those registered by the track-caps device. Since participants were instructed to take their first sample when they woke up, the time of the first sample was used as the wake-up time. For the small number of days for which no first sample was collected, but at least one of the other samples was, the wake-up time recorded on the daily questionnaire was used instead (40/2899, 1.4\%). Days missing both the first sample and the reported wake-up time $(5 / 2899,0.2 \%)$ were excluded.

The 1002 participants enrolled in the MESA Stress Study yielded a maximum of 3006 participant-days of data collection. Of these 127 days were excluded because no track-caps times were available ( $n=107$ days), no cortisol samples were collected ( $n=15$ days), or because there was no first cap time or reported wake-up time to use for a wake-up time $(n=5$ days). We excluded 936 samples with no track-cap time, insufficient sample for assay, or unreliable cortisol value $(0$ or $>100 \mathrm{nmol} / \mathrm{L})$. Lastly we excluded those that reported taking oral or inhaled steroids ( $n=35$ persons). This resulted in a total of 935 participants, 2774 days, and 15,774 samples for analysis.

\section{Results}

Table 1 shows selected characteristics of study participants by site, age, sex, race/ethnicity and SES indicators. The median age of the participants was 65 years. Approximately $49 \%$ of the sample was male, $20 \%$ were white, $28 \%$ black, and $53 \%$ Hispanic. Approximately $85 \%$ of participants collected at least five samples per day for all days on which they collected samples ( $97 \%$ of participants collected samples on all 3 days). The percentage of participants with at least five samples per day was similar across socio-demographic characteristics. Overall $86 \%$ of self-recorded times were within $15 \mathrm{~min}$ of the registered track-cap times a measure of time-recording accuracy. Younger participants, whites, and participants with higher SES showed higher percentages of time-recording accuracy ( $p<0.001$ for all comparisons).

Overall the first sample was taken within 5 min of wake-up for $78 \%$ of days across participants. Again this measure of concordance was higher among younger people, whites and participants with higher SES. The median wake-up time (first sample) was $0642 \mathrm{~h}$ and the median bedtime (last sample) was $2226 \mathrm{~h}$. Older people reported later wake-up times $(p=0.005)$, and higher income persons reported later bedtimes $(p=0.004)$. A few other SES variables also showed significant differences in bedtimes. The median time difference between the first and second sample was $34 \mathrm{~min}$ and did not vary substantially by demographic characteristics. The AUC for cortisol increased with age ( $p$ for trend 0.0003 ) and was higher in whites than minorities $(p=0.002)$. There were no significant differences by site, gender, income, wealth or education.

Fig. 1 shows smoothed LOESS curves for cortisol daily profiles stratified by age, sex, race/ethnicity and income/ wealth. In general cortisol values were higher in older than in younger participants. This difference was most pronounced later in the day, suggesting flatter declines as age increased. Males generally had higher cortisol values than females, except later in the day, when values were similar or slightly higher for females. Cortisol levels were higher in whites than in blacks at wake-up and 30 min after wake-up, but blacks had a slower decline later in the day resulting in slightly higher levels than whites before bedtime. Hispanics tended to have lower cortisol levels than other groups overall. Persons in the lowest income/wealth category had less pronounced increases after wake-up and less steep declines later in the day.

Table 2 shows percent differences in different aspects of the daily cortisol profile associated with race/ethnicity, and income/wealth. Separate estimates are shown for cortisol at wake-up and for three different portions of change over the day: (1) CAR or the morning rise (the increase between wakeup and $30 \mathrm{~min}$ ), (2) the decline between 30 and 120 min after wake-up (henceforth referred to as "early decline") and (3) the decline between 120 min after wake-up and bedtime (henceforth referred to as "late decline"). All estimates were obtained simultaneously from a piecewise linear mixed model and were adjusted for race/ethnicity, income-wealth index, age, sex, day and wake-up time. Models adjusted for health behaviors (smoking, exercise and obesity), psychosocial factors (cynical hostility, depression, emotional support and chronic burden) and both health behaviors and psychosocial factors are also presented in Table 2. Positive percent differences in wake-up levels indicate higher cortisol levels. Positive percent differences in the CAR indicate a more pronounced or steeper increase and positive percent differences in the early or late decline indicate a less pronounced or flatter decline.

In the minimally adjusted model (adjusted for age, sex, day, wake-up time, race/ethnicity and the income-wealth index) blacks and Hispanics had significantly lower levels of cortisol than whites at wake-up $(-17.2 \%$ and $-15.7 \%$ lower in blacks and Hispanics, respectively, $p \leqq 0.005$ for both comparisons). They also had a less pronounced CAR than whites but these differences were not statistically significant. Both groups also had less pronounced early declines than whites (7.1\% for blacks $p$-value 0.068 and $12.0 \%$ for Hispanic $p$ value $<0.001)$. The late decline was also significantly less pronounced in blacks than in whites but in contrast Hispanics had a more pronounced late decline than whites, although differences in the late decline were very small.

Adjustment for behavioral or psychosocial factors did not substantially modify point estimates, although reductions (e.g. in differences at wake-up) were observed. Overall, the general pattern of lower wake-up, less pronounced CAR and less steep early decline observed in Blacks and Hispanics compared to whites persisted after adjustment.

Persons with the lowest levels of income/wealth (score of zero on the combined income-wealth index) had $18.2 \%(\mathrm{Cl}$ : $3.4,35.1)$ lower wake-up levels compared to those with the highest income/wealth score (score of eight). Lower income/ wealth was also associated with a less pronounced early and late decline, although differences in the late decline were small and were not statistically significant. As in the case of differences by race/ethnicity, point estimates were largely unchanged after adjustment for behavioral and psychosocial 

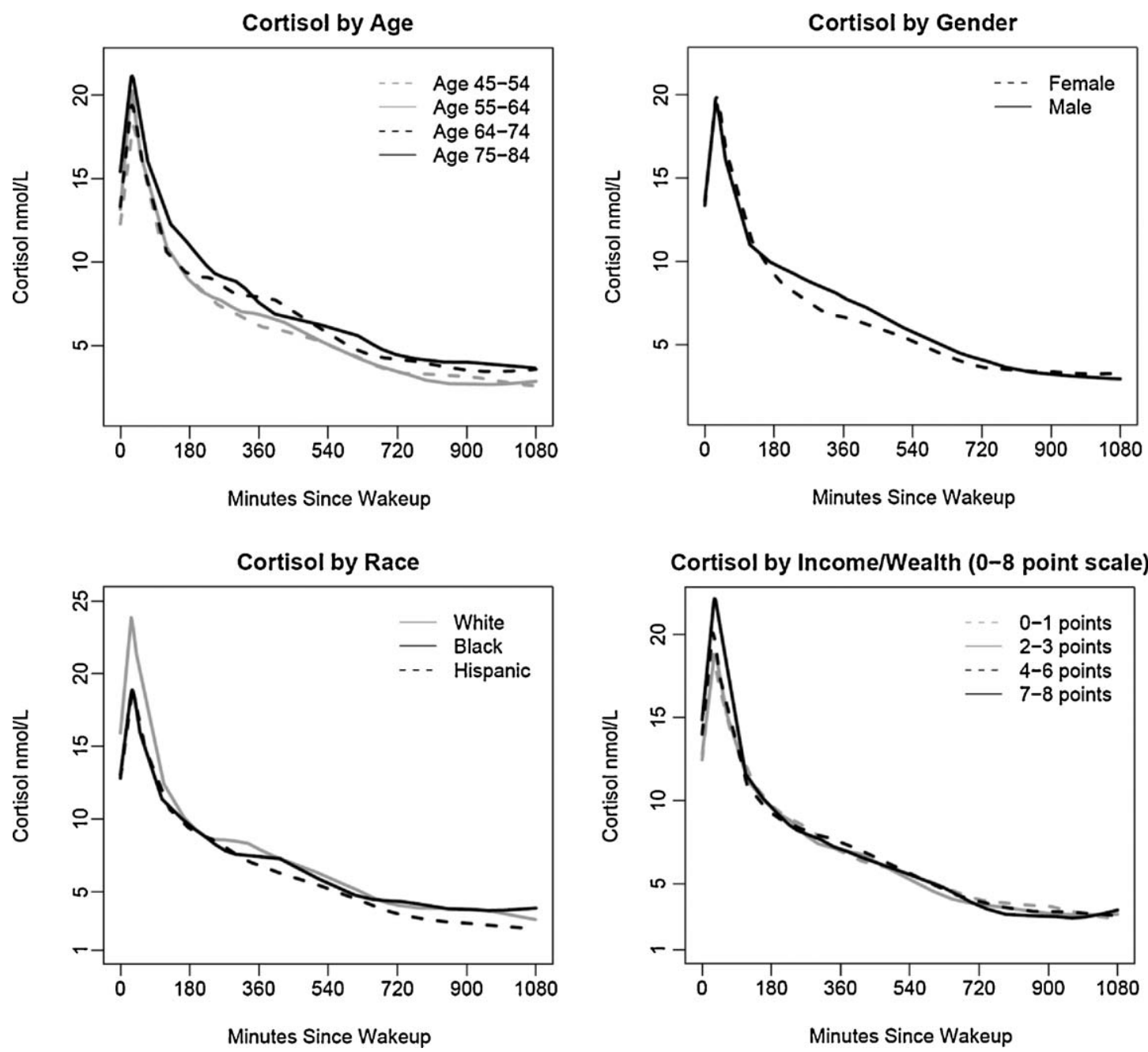

Figure 1 LOESS curves of cortisol by age, gender, race and income/wealth.

factors, and differences in wake-up values and early decline remained statistically significant.

Wealth was largely driving the observed associations of cortisol with the combined income-wealth index (results not shown, but percent differences are similar to those presented in Table 2). In fact, in the fully adjusted model the 5 -point wealth index showed slightly stronger associations at wake-up and early decline than did the combined variable (18.7\% less cortisol at wake-up for the least wealthy; $18.7 \%$ less pronounced early decline among the least wealthy). In contrast, income and education were associated with relatively small non-significant percent changes over the day.

Table 3 shows mean differences in the AUC associated with race/ethnicity and income/wealth. Hispanics consistently had a significantly smaller AUC compared to whites (1261.2 less according to the fully adjusted model, $\mathrm{Cl}$ : $-2074.0,-448.5)$. Blacks, however, were not significantly different from whites after controlling for health behaviors or psychosocial factors. Similarly the income-wealth index showed no association with AUC, nor did wealth, income or education (results not shown).

Several sensitivity analyses were conducted. First, alternate ways of creating the income-wealth index were explored, but the version used here provided the most detail without losing much power. Including employment status to the model did not change estimates appreciably, so it was not included in the final model for the sake of parsimony. In addition, two participants reported oral contraception (OC) use, a common confounder in cortisol studies (Kirschbaum et al., 1995). Adjusting for OC use made little difference to the estimates; therefore it was not included in the final model. Other research has pointed to seasonal changes in cortisol levels (King et al., 2000); controlling for season in which the sample was collected also made little difference to our results. In addition, to assess concerns about timing of morning cortisol samples, findings were similar when analyses were restricted to the 2185 days where the first sample and the reported wakeup time were within 5 min of each other. Lastly, results were robust to alternate specifications of the second knot in the mixed model. We attempted to place the second knot at 90 , 120 , and 210 min but 120 min provided the best fit and yielded a more precise estimate of the early decline compared to approaches that placed the knot earlier in the day.

\section{Discussion}

This study found evidence of associations of daily cortisol profiles with race/ethnicity and SES. Hispanics, blacks and 
Table 2 Percent differences (95\% confidence intervals) in log wake-up cortisol, log cortisol awakening response, early and late decline in log cortisol ( $\mathrm{nmol} / \mathrm{L})$ associated with race/ethnicity and income-wealth index, controlling for health behaviors and psychosocial factors.

\begin{tabular}{|c|c|c|c|}
\hline & \multicolumn{2}{|l|}{ Race $^{a}$} & \multirow{2}{*}{$\begin{array}{l}\text { SES }^{\mathrm{b}} \\
\text { Income-wealth index }\end{array}$} \\
\hline & Blacks & Hispanic & \\
\hline \multicolumn{4}{|l|}{ Percent difference at wake-up } \\
\hline Minimally adjusted model ${ }^{\mathrm{c}}$ & $-17.2(-30.0,-5.7)$ & $-15.7(-28.2,-4.5)$ & $18.2(3.4,35.1)$ \\
\hline Model controlling for health behaviors ${ }^{d}$ & $-12.1(-24.6,-0.9)$ & $-10.9(-23.3,0.2)$ & $17.4(2.4,34.6)$ \\
\hline Model controlling for psychosocial factors ${ }^{\mathrm{e}}$ & $-15.7(-28.5,-4.1)$ & $-14.3(-26.9,-3.0)$ & $17.1(1.7,34.8)$ \\
\hline $\begin{array}{l}\text { Model controlling for health behaviors } \\
\text { and psychosocial factors }{ }^{f}\end{array}$ & $-10.5(-23.0,0.7)$ & $-9.4(-21.9,1.8)$ & $15.9(0.5,33.7)$ \\
\hline \multicolumn{4}{|l|}{ Percent difference in cortisol awakening response } \\
\hline Minimally adjusted model ${ }^{c}$ & $-13.0(-35.6,6.3)$ & $-15.0(-37.4,3.8)$ & $0.02(-27.4,27.4)$ \\
\hline Model controlling for health behaviors ${ }^{d}$ & $-15.4(-39.5,4.7)$ & $-18.1(-42.8,2.4)$ & $4.3(-22.9,33.7)$ \\
\hline Model controlling for psychosocial factors ${ }^{\mathrm{e}}$ & $-12.3(-35.5,7.5)$ & $-14.4(-37.4,4.9)$ & $-2.2(-31.2,25.7)$ \\
\hline $\begin{array}{l}\text { Model controlling for both health behaviors } \\
\text { and psychosocial factors }{ }^{f}\end{array}$ & $-15.9(-40.9,5.0)$ & $-18.9(-44.7,2.4)$ & $2.8(-25.3,32.4)$ \\
\hline \multicolumn{4}{|l|}{ Percent difference at early decline } \\
\hline Minimally adjusted model ${ }^{\mathrm{C}}$ & $7.1(-0.5,15.2)$ & $12.0(4.8,19.7)$ & $-14.1(-26.2,-3.1)$ \\
\hline Model controlling for health behaviors ${ }^{d}$ & $6.7(-1.0,15.0)$ & $10.3(3.0,18.3)$ & $-15.9(-28.4,-4.6)$ \\
\hline Model controlling for psychosocial factors ${ }^{\mathrm{e}}$ & $6.3(-1.5,14.6)$ & $11.2(3.8,19.2)$ & $-11.2(-23.7,-0.01)$ \\
\hline $\begin{array}{l}\text { Model controlling for both health behaviors } \\
\text { and psychosocial factors }\end{array}$ & $6.2(-1.7,14.7)$ & $10.1(2.4,18.3)$ & $-12.9(-25.7,-1.5)$ \\
\hline \multicolumn{4}{|l|}{ Percent difference at late decline } \\
\hline Minimally adjusted model ${ }^{c}$ & $1.7(0.7,2.8)$ & $-2.1(-3.1,-1.1)$ & $-1.1(-2.4,0.2)$ \\
\hline Model controlling for health behaviors ${ }^{d}$ & $1.5(0.4,2.6)$ & $-2.1(-3.1,-1.0)$ & $-0.9(-2.3,0.4)$ \\
\hline Model controlling for psychosocial factors ${ }^{\mathrm{e}}$ & $1.9(0.8,3.0)$ & $-2.0(-3.0,-0.9)$ & $-1.2(-2.6,0.1)$ \\
\hline $\begin{array}{l}\text { Model controlling for both health behaviors } \\
\text { and psychosocial factors }{ }^{f}\end{array}$ & $1.6(0.5,2.7)$ & $-1.9(-3.0,-0.8)$ & $-1.0(-2.4,0.3)$ \\
\hline \multicolumn{4}{|c|}{$\begin{array}{l}\text { a Referent group for race is White non-Hispanic. } \\
\text { b Percent difference for income--wealth index reflects 8-point change from } 0 \text { (lowest income-wealth category) to } 8 \text { (highest income- } \\
\text { wealth category) on income-wealth scale. } \\
{ }^{c} \text { Minimally adjusted model controls for race/ethnicity, income-wealth index, age, sex, day, and wake-up time. } \\
{ }^{d} \text { Model controlling for health behaviors includes smoking, body mass index and physical activity and all factors in minimally adjusted } \\
\text { model. } \\
\text { e Model controlling for psychosocial factors includes cynical hostility, depression, emotional support and chronic burden and all factors in } \\
\text { minimally adjusted model. } \\
{ }_{f}^{f} \text { Includes covariates in minimally adjusted model, psychosocial factors and health behaviors. }\end{array}$} \\
\hline
\end{tabular}

low SES individuals had lower cortisol at wake-up and slower declines over the day (especially the earlier part of the day). Differences in declines later in the day were very small, but in general a less pronounced decline was associated with being black and having low income/wealth, while a more pronounced decline was associated with being Hispanic. No significant differences by income/wealth were observed for AUC cortisol and only one for race/ethnicity: Hispanics had significantly lower AUC than whites.

Although work in this area has grown exponentially over the past few years, relatively few studies have investigated differences by race/ethnicity and SES in features of the cortisol curve. Studies have varied widely in sample size, selection criteria, and number of measures collected. A relatively consistent finding that has emerged is the presence of a higher evening cortisol levels in Blacks compared to white. Two studies reported this finding, one in adults and another in youth (Cohen et al., 2006b; DeSantis et al., 2007). These studies, however, did not report the decline during evening hours but rather the level of cortisol taken at evening measurements.

Studies with numerous repeat daily cortisol measurements have demonstrated similar results to ours (Cohen et al., 2006b; DeSantis et al., 2007). Although these studies did not use the same analytic approach as we did, our results confirmed the presence of a less steep daily decline in Blacks compared to whites and in low SES compared to high SES persons in a large population sample with measures over 3 days. However, the differences we observed were more robust in the earlier rather than in the later decline. This could be due to the very low levels of cortisol present in the body during evening hours making differences more difficult to detect. We further expanded prior work by showing that the less steep early decline was also observed in Hispanic compared to whites. Only one other study examined cortisol in a US Hispanic population and found higher bedtime cortisol levels among Hispanics compared to whites (prior to adjusting for SES) and flatter cortisol slopes (DeSantis et al., 2007). 
Table 3 Mean differences and 95\% confidence intervals in cortisol measured as area under the curve (nmol/L min) associated with race/ethnicity and income-wealth index.

\begin{tabular}{|c|c|c|c|c|c|c|}
\hline & \multicolumn{4}{|l|}{ Race $^{a}$} & \multirow{2}{*}{\multicolumn{2}{|c|}{$\begin{array}{l}\text { SES }^{\mathrm{b}} \\
\text { Income-wealth index }\end{array}$}} \\
\hline & \multicolumn{2}{|l|}{ Blacks } & \multicolumn{2}{|l|}{ Hispanics } & & \\
\hline & $\begin{array}{l}\text { Mean } \\
\text { difference }\end{array}$ & $\begin{array}{l}95 \% \text { confidence } \\
\text { interval }\end{array}$ & $\begin{array}{l}\text { Mean } \\
\text { difference }\end{array}$ & $\begin{array}{l}95 \% \text { confidence } \\
\text { interval }\end{array}$ & $\begin{array}{l}\text { Mean } \\
\text { difference }\end{array}$ & $\begin{array}{l}95 \% \text { confidence } \\
\text { interval }\end{array}$ \\
\hline Minimally adjusted model $^{\mathrm{C}}$ & -797.2 & $-1569.2,-25.1$ & -1261.2 & $-2074.0,-448.5$ & -208.0 & $-1198.7,782.8$ \\
\hline $\begin{array}{l}\text { Model controlling for } \\
\text { health behaviors }\end{array}$ & -668.4 & $-1503.8,167.1$ & -1225.3 & $-2085.7,-364.8$ & -223.1 & $-1244.9,798.6$ \\
\hline $\begin{array}{l}\text { Model controlling for } \\
\text { psychosocial factors }\end{array}$ & -688.2 & $-1461.5,85.1$ & -1192.0 & $-2009.5,-374.5$ & -181.3 & $-1261.0,898.5$ \\
\hline $\begin{array}{l}\text { Model controlling for } \\
\text { both health behaviors and } \\
\text { psychosocial factors }^{f}\end{array}$ & -548.9 & $-1384.0,286.2$ & -1117.6 & $-1980.8,-254.4$ & -182.0 & $-1279.3,915.3$ \\
\hline $\begin{array}{l}\text { a Referent group for Blacks an } \\
\text { b Mean differences for income } \\
\text { category) on income--wealth sc } \\
{ }^{c} \text { Minimally adjusted model co } \\
{ }^{d} \text { Model controlling for health } \\
\text { model. } \\
{ }^{e} \text { Model controlling for psychos } \\
\text { minimally adjusted model. } \\
{ }^{f} \text { Includes covariates in minim }\end{array}$ & $\begin{array}{l}\text { Hispanics is } \\
\text {-wealth refle } \\
\text { le. } \\
\text { trols for race } \\
\text { ehaviors incl } \\
\text { cial factors in } \\
\text { Illy adjusted }\end{array}$ & $\begin{array}{l}\text { Vhite. } \\
\text { ts 8-point change } f \\
\text { 'ethnicity, income- } \\
\text { des smoking, body } \\
\text { ludes cynical hostil } \\
\text { odel, psychosocial }\end{array}$ & $\begin{array}{l}\text { m } 0 \text { (lowest } \\
\text { lealth index, } \\
\text { lass index and } \\
\text { y, depression, }\end{array}$ & $\begin{array}{l}\text { come-wealth categ } \\
\text { ge, sex and wake-up } \\
\text { physical activity and } \\
\text { emotional support an } \\
\text { th behaviors. }\end{array}$ & $\begin{array}{l}\text { y) to } 8 \text { (highe } \\
\text { ime. } \\
\text { all factors in } \\
\text { chronic burde }\end{array}$ & $\begin{array}{l}\text { st income-wealth } \\
\text { inimally adjusted } \\
\text { and all factors in }\end{array}$ \\
\hline
\end{tabular}

We also found persistent differences by race/ethnicity and SES in wake-up values. Wake-up cortisol levels have been studied much more widely than features of the diurnal pattern and have resulted in the emergence of a very mixed overall picture. Similar to our results, several studies reported whites had higher cortisol levels at wake-up than blacks (Bennett et al., 2004; Cohen et al., 2006b; DeSantis et al., 2007) and high SES participants had higher morning cortisol levels than low SES participants (Brandtstädter et al., 1991; Steptoe et al., 2003; Bennett et al., 2004). However, two studies found the opposite association with SES (Ockenfels et al., 1995; Garcia et al., 2008), while several others found no association between wake-up levels of cortisol and SES (Kunz-Ebrecht et al., 2004; Ranjit et al., 2005a; Wright and Steptoe, 2005; Cohen et al., 2006a,b; Eller et al., 2006). This study and others with larger, more diverse populations and denser cortisol sampling during the day consistently found whites and high SES groups had higher levels of cortisol upon awakening (Brandtstädter et al., 1991; Cohen et al., 2006b; DeSantis et al., 2007).

The cortisol awakening response is thought by some to be the most important piece of the diurnal cortisol pattern, thus it has been the subject of much examination (Clow et al., 2004). As it relates to SES, results thus far have been mixed. Among studies that found an association between SES and CAR, a few found CAR was steeper in low SES populations (Kunz-Ebrecht et al., 2004; Wright and Steptoe, 2005), while others found CAR to be steeper among populations in better economic situations (Bennett et al., 2004; Ranjit et al., 2005b). Similar to our results, several studies found no association between SES and CAR (Steptoe et al., 2003; Cohen et al., 2006b; Eller et al., 2006; Garcia et al., 2008). We did, however, find some evidence that the CAR was less pronounced in Blacks and Hispanics compared to whites. Cohen et al. (2006b) and Bennett et al. (2004) were the only other studies to look at the association between race and CAR and found no association. AUC was another measure of cortisol found in the literature. Unlike other studies that found low SES individuals had higher AUC (Cohen et al., 2006a; Li et al., 2007; Garcia et al., 2008), our results showed little association between current SES measures (income, education, wealth or combined income-wealth) and AUC. The association between AUC and race revealed an interesting finding. To our knowledge, ours is the first study to find an association between Hispanics and AUC, where Hispanics have less total AUC relative to whites.

A number of stress related mechanisms could explain our findings of differences in wake-up values, late decline, and possibly CAR by SES and or race/ethnicity. It has been hypothesized that in the face of an acute stressor cortisol levels increase, however, as the stressor becomes chronic and with the passage of time a below-normal cortisol response is observed. The lower levels of cortisol at wake-up and during the CAR for blacks, Hispanics and the poor are consistent with this chronic stress theory. The higher mid-day cortisol levels may be a result of stressful daily experiences (Miller et al., 2007). The activation of the HPA axis during day time hours and after specific race-related incidents has been observed by other studies (Steptoe et al., 2003; Miller et al., 2007; Richman and Jonassaint, 2008) and is consistent with the observed higher mid-day cortisol levels in our study. As a summary measure of cortisol, AUC may not be capturing the intricacies of the diurnal cortisol pattern. Although our piecewise models found significant differences at wake-up and early decline, no association was evident with our measure of AUC.

A number of behavioral and psychosocial factors could confound and/or mediate SES or race/ethnicity differences in cortisol. The cross-sectional nature of our analyses did not allow us to separate confounders from mediators. The inclu- 
sion of these variables in our models did not substantially change the general patterns. These results suggested that the associations are at least partly independent of these factors. However measurement error in these covariates could have affected our results. Additional work with improved measurement and longitudinal data will be necessary to better understand the behavioral and/or psychosocial processes mediating SES or race/ethnicity effects on cortisol.

Since the study of cortisol in large populations is relatively new, there is limited epidemiologic evidence that helps explain the consequences of cortisol dysregulation. A few papers have reported an association between cortisol and indicators of early atherosclerosis such as coronary calcification and intima media thickness (Eller et al., 2001; Matthews et al., 2006). Others have found an association between cortisol and inflammation (Petrovsky et al., 1998; Miller et al., 2002), obesity (Bjorntorp, 1997; Epel et al., 2000) and hypertension (Rosmond and Bjorntorp, 2000; Hammer and Stewart, 2006), all important risk factors that could lead to poor cardiovascular disease outcomes. A better understanding of the importance of atypical diurnal cortisol patterns will require additional work.

Our study had limitations. First, although we observed effects during the later part of the day, only two samples were collected in the evening hours. Second, many studies have documented non-compliance to the study protocol, specifically with morning samples, resulting in misleading cortisol curves in the morning hours (Clow et al., 2004; KunzEbrecht et al., 2004; Wright and Steptoe, 2005). Although our study improved upon past research by using track-caps to ensure better adherence, the accuracy of the wake-up sample was still uncertain. In addition, although we were able to collect three days of cortisol samples, there was still some uncertainty about the stability of cortisol measurements over time. Lastly, our use of the combined incomewealth index as our main measure of SES was a departure from other studies. Since we are unable to compare it to other studies, it is unclear if the results produced will be replicated in the future. It should be noted, however, that wealth has been shown to be a better measure of SES among older retired populations (Keister and Moller, 2000; Pollack et al., 2007). Since over half of our sample was older than 65 years old and almost $45 \%$ indicated their employment status as retired, we feel the use of wealth was appropriate in this study.

Our study improved upon past studies of salivary cortisol in its sampling approach (taking six samples over 3 days), sample size (almost 1000 individuals) and large Hispanic population. Our study was one of the few to examine a large Hispanic population and to find significant difference in the slope of the cortisol curve for Hispanics compared to whites. In addition the use of track-caps to record the time samples were taken helped reduce issues with compliance that several observational studies have noted. Lastly, our use of piecewise linear models to analyze cortisol data allowed flexibility in modeling and yielded more specific results of which features of the cortisol curve were associated with race/ethnicity and SES. This approach did raise issues about the independence of the different pieces of the cortisol curve; such that the inference about one piece of the curve may be correlated to the inference about another piece. However, the correlations between the estimated pieces of the curve were low to moderate (range 0.02-0.44), minimizing this concern.

In future work on cortisol and race/ethnicity and SES it would be useful to collect additional evening samples in order to produce more robust measurements of cortisol patterns later in the day. Our study was one of the few to suggest that declines in the later portion of the day were association with race/ethnicity and SES. In addition, cortisol measurements in large multi-ethnic study populations are needed. This would enhance our understanding of how diurnal cortisol patterns differ among different race/ethnic group and could potentially corroborate the results we observed. Lastly, repeat cortisol measures taken over the course of time would help us understand the stability (or instability) of cortisol in an individual over time.

\section{Role of the funding sources}

MESA was supported by contracts N01-HC-95159 through N01HC-95169 from the National Heart, Lung, and Blood Institute (NHLBI). NHLBI had no further role in the study design; in the collection, analysis and interpretation of data; in the writing of the report; and in the decision to submit the paper for publication. This research was also supported in part by the Michigan Center for Integrative Approaches to Health Disparities (P60MD002249) funded by the National Center on Minority Health and Health Disparities.

\section{Conflict of interest}

All authors declare they have no conflicts of interest.

\section{Acknowledgements}

The authors thank the other investigators, the staff, and the participants of the MESA study for their valuable contributions. A full list of participating MESA investigators and institutions can be found at http://www.mesa-nhlbi.org.

\section{References}

Adler, N.E., Boyce, T., Chesney, M.A., Cohen, S., Folkman, S., Kahn, R.L., Syme, S.L., 1994. Socioeconomic status and health. The challenge of the gradient. Am. Psychol. 49, 15-24.

Barefoot, J.C., Dodge, K.A., Peterson, B.L., Dahlstrom, W.G., Williams Jr., R.B., 1989. The Cook-Medley hostility scale: item content and ability to predict survival. Psychosom. Med. 51, 46-57.

Baum, A., Garofalo, J.P., Yali, A.M., 1999. Socioeconomic status and chronic stress. Does stress account for SES effects on health? Ann. N. Y. Acad. Sci. 896, 131-144.

Bennett, G.G., Merritt, M.M., Wolin, K.Y., 2004. Ethnicity, education, and the cortisol response to awakening: a preliminary investigation. Ethn. Health 9, 337-347.

Bild, D.E., Bluemke, D.A., Burke, G.L., Detrano, R., Diez Roux, A.V., Folsom, A.R., Greenland, P., Jacob Jr., D.R., Kronmal, R., Liu, K., Nelson, J.C., O'Leary, D., Saad, M.F., Shea, S., Szklo, M., Tracy, R.P., 2002. Multi-ethnic study of atherosclerosis: objectives and design. Am. J. Epidemiol. 156, 871-881.

Bjorntorp, P., 1997. Body fat distribution, insulin resistance, and metabolic diseases. Nutrition 13, 795-803. 
Brandtstädter, J., Baltes-Götz, B., Kirschbaum, C., Hellhammer, D., 1991. Developmental and personality correlates of adrenocortical activity as indexed by salivary cortisol: observations in the age range of 35 to 65 years. J. Psychosom. Res. 35, 173-185.

Bromberger, J.T., Matthews, K.A., 1996. A longitudinal study of the effects of pessimism, trait anxiety, and life stress on depressive symptoms in middle-aged women. Psychol. Aging 11, 207-213.

Brunner, E., 1997. Stress and the biology of inequality. BMJ 314, 1472-1476.

Cleveland, W.S., Devlin, S.J., Grosse, E., 1988. Regression by local fitting: methods, properties, and computational algorithms. J. Econom. 37, 87-114.

Clow, A, Thorn, L., Evans, P., Hucklebridge, F., 2004. The awakening cortisol response: methodological issues and significance. Stress 7, 29-37.

Cohen, S., Doyle, W.J., Baum, A., 2006a. Socioeconomic status is associated with stress hormones. Psychosom. Med. 68, 414-420.

Cohen, S., Gordon, L.U., Kessler, R.C., 1995. Measuring Stress: A Guide for Health and Social Scientists. Oxford University Press, New York.

Cohen, S., Schwartz, J.E., Epel, E., Kirschbaum, C., Sidney, S., Seeman, T., 2006b. Socioeconomic status, race, and diurnal cortisol decline in the Coronary artery risk development in young adults (Cardia) study. Psychosom. Med. 68, 41-50.

Decker, S.A., 2000. Salivary cortisol and social status among Dominican men. Horm. Behav. 38, 29-38.

DeSantis, A.S., Adam, E.K., Doane, L.D., Mineka, S., Zinbarg, R.E., Craske, M.G., 2007. Racial/ethnic differences in cortisol diurnal rhythms in a community sample of adolescents. J. Adolesc. Health 41, 3-13.

Devlin, S.J., Cleveland, W.S., 1988. Locally weighted regression: an approach to regression analysis by local fitting. J. Am. Stat. Assoc. 83 (515), 596.

Eller, N.H., Netterstrom, B., Hansen, A.M., 2001. Cortisol in urine and saliva: relations to the intima media thickness, IMT. Atherosclerosis $159,175-185$.

Eller, N.H., Netterstrom, B., Hansen, A.M., 2006. Psychosocial factors at home and at work and levels of salivary cortisol. Biol. Psychol. 73, 280-287.

Epel, E.S., McEwen, B., Seeman, T., Matthews, K., Castellazzo, G., Brownell, K.D., Bell, J., Ickovics, J.R., 2000. Stress and body shape: stress-induced cortisol secretion is consistently greater among women with central fat. Psychosom. Med. 62, 623-632.

Garcia, M.C., de Souza, A., Bella, G.P., Grassi-Kassisse, D.M., Tacla, A.P., Spadari-Bratfisch, R.C., 2008. Salivary cortisol levels in Brazilian citizens of distinct socioeconomic and cultural levels. Ann. N. Y. Acad. Sci. 1148, 504-508.

Hammer, F., Stewart, P.M., 2006. Cortisol metabolism in hypertension. Best Pract. Res. Clin. Endocrinol. Metab. 20, 337-353.

Hansen, A.M., Garde, A.H., Persson, R., 2008. Sources of biological and methodological variation in salivary cortisol and their impact on measurement among healthy adults: a review. Scand. J. Clin. Lab. Invest. 68, 448-458.

Irwin, M.L., Mayer-Davis, E.J., Addy, C.L., Pate, R.R., Durstine, J.L., Stolarczyk, L.M., Ainsworth, B.E., 2000. Moderate-intensity physical activity and fasting insulin levels in women: the cross-cultural activity participation study. Diabetes Care 23, 449-454.

Keister, L.A., Moller, S., 2000. Wealth inequality in the United States. Annu. Rev. Sociol. 26, 63-81.

King, J., Rosal, M.C., Ma, Y., Reed, G., Kelly, T.A., Stanek 3rd, E.J., Ockene, I.S., 2000. Sequence and seasonal effects of salivary cortisol. Behav. Med. 26, 67-73.

Kirschbaum, C., Pirke, K.M., Hellhammer, D.H., 1995. Preliminary evidence for reduced cortisol responsivity to psychological stress in women using oral contraceptive medication. Psychoneuroendocrinology 20, 509-514.

Kudielka, B.M., Broderick, J.E., Kirschbaum, C., 2003. Compliance with saliva sampling protocols: electronic monitoring reveals invalid cortisol daytime profiles in noncompliant subjects. Psychosom. Med. 65, 313-319.

Kunz-Ebrecht, S.R., Kirschbaum, C., Marmot, M., Steptoe, A., 2004. Differences in cortisol awakening response on work days and weekends in women and men from the Whitehall II cohort. Psychoneuroendocrinology 29, 516-528.

Li, L., Power, C., Kelly, S., Kirschbaum, C., Hertzman, C., 2007. Lifetime socio-economic position and cortisol patterns in mid-life. Psychoneuroendocrinology 32, 824-833.

Matthews, K., Schwartz, J., Cohen, S., Seeman, T., 2006. Diurnal cortisol decline is related to coronary calcification: Cardia study. Psychosom. Med. 68, 657-661.

Miller, G.E., Chen, E., Zhou, E.S., 2007. If it goes up, must it come down? Chronic stress and the hypothalamic-pituitary-adrenocortical axis in humans. Psychol. Bull. 133, 25-45.

Miller, G.E., Cohen, S., Ritchey, A.K., 2002. Chronic psychological stress and the regulation of pro-inflammatory cytokines: a glucocorticoid-resistance model. Health Psychol. 21, 531541.

Ockenfels, M.C., Porter, L., Smyth, J., Kirschbaum, C., Hellhammer, D.H., Stone, A.A., 1995. Effect of chronic stress associated with unemployment on salivary cortisol: overall cortisol levels, diurnal rhythm, and acute stress reactivity. Psychosom. Med. 57, 460467.

Pearlin, L.I., Schieman, S., Fazio, E.M., Meersman, S.C., 2005. Stress, health, and the life course: some conceptual perspectives. J. Health Soc. Behav. 46, 205-219.

Petrovsky, N., McNair, P., Harrison, L.C., 1998. Diurnal rhythms of pro-inflammatory cytokines: regulation by plasma cortisol and therapeutic implications. Cytokine 10, 307-312.

Pollack, C.E., Chideya, S., Cubbin, C., Williams, B., Dekker, M., Braveman, P., 2007. Should health studies measure wealth? A systematic review. Am. J. Prev. Med. 33, 250-264.

Pope, M.K., Smith, T.W., 1991. Cortisol excretion in high and low cynically hostile men. Psychosom. Med. 53, 386-392.

Pruessner, M., Hellhammer, D.H., Pruessner, J.C., Lupien, S.J., 2003. Self-reported depressive symptoms and stress levels in healthy young men: associations with the cortisol response to awakening. Psychosom. Med. 65, 92-99.

Radloff, L., 1977. The CES-D scale: a self-report depression scale for research in the general population. Appl. Psychol. Meas. 1, 385.

Ranjit, N., Diez Roux, A.V., Sanchez, B., Seeman, T., Shea, S., Shrager, S., Watson, K., 2009. Association of salivary cortisol circadian pattern with cynical hostility: the multi-ethnic study of atherosclerosis. Psychosom. Med. 71, 748-755.

Ranjit, N., Young, E.A., Kaplan, G.A., 2005a. Material hardship alters the diurnal rhythm of salivary cortisol. Int. J. Epidemiol. 34, $1138-1143$.

Ranjit, N., Young, E.A., Raghunathan, T.E., Kaplan, G.A., 2005b. Modeling cortisol rhythms in a population-based study. Psychoneuroendocrinology 30, 615-624.

Richman, L.S., Jonassaint, C., 2008. The effects of race-related stress on cortisol reactivity in the laboratory: implications of the duke lacrosse scandal. Ann. Behav. Med. 35, 105-110.

Rosmond, R., Bjorntorp, P., 2000. The hypothalamic-pituitary-adrenal axis activity as a predictor of cardiovascular disease, type 2 diabetes and stroke. J. Intern. Med. 247, 188-197.

Sjogren, E., Leanderson, P., Kristenson, M., 2006. Diurnal saliva cortisol levels and relations to psychosocial factors in a population sample of middle-aged Swedish men and women. Int. J. Behav. Med. 13, 193-200.

Steptoe, A., Brydon, L., Kunz-Ebrecht, S., 2005. Changes in financial strain over three years, ambulatory blood pressure, and cortisol responses to awakening. Psychosom. Med. 67, $281-287$.

Steptoe, A., Kunz-Ebrecht, S., Owen, N., Feldman, P.J., Willemsen, G., Kirschbaum, C., Marmot, M., 2003. Socioeconomic status and 
stress-related biological responses over the working day. Psychosom. Med. $65,461-470$.

Steptoe, A., Marmot, M., 2002. The role of psychobiological pathways in socio-economic inequalities in cardiovascular disease risk. Eur. Heart J. 23, 13-25.

Wright, C.E., Steptoe, A., 2005. Subjective socioeconomic position, gender and cortisol responses to waking in an elderly population. Psychoneuroendocrinology 30, 582-590.
Yeh, K.C., Kwan, K.C., 1978. A comparison of numerical integrating algorithms by trapezoidal, lagrange, and spline approximation. J. Pharmacokinet. Biopharm. 6, 79-98.

Yehuda, R., Teicher, M.H., Trestman, R.L., Levengood, R.A., Siever, L.J., 1996. Cortisol regulation in posttraumatic stress disorder and major depression: a chronobiological analysis. Biol. Psychiatry $40,79-88$. 